\title{
Doğal ve Modifiye Edilmiş Sepiyolit ile Sulu Çözeltilerden Arsenik ve Manganın Adsorpsiyonu ile Ayrımı
}

\author{
*1 Ayten Ateş, ${ }^{2}$ Gökhan Yaşar \\ ${ }^{1}$ Cumhuriyet Üniversitesi, Mühendislik Fakültesi, Kimya Mühendisliği Böl., 58140 Sivas/Türkiye, aytates@ gmail.com, \\ ${ }^{1}$ Cumhuriyet Üniversitesi, Mühendislik Fakültesi, Kimya Mühendisliği Böl., 58140 Sivas/Türkiye, gkhysr40@gmail.com, \\ Araştırma Makalesi \\ Geliş Tarihi: 07.04.2018 \\ Kabul Tarihi: 16.11 .2018
}

$\ddot{O} z$

Doğal sepiyolit kil minerali Türkiye'nin Maden Tetkik ve Arama (MTA) kurumundan sağlanmış ve $2.5 \mathrm{M}$ NaOH ile modifiye edilmiştir. Doğal (SP) ve modifiye edilmiş sepiyolit (Na-SP) örnekleri XRD, $\mathrm{N}_{2}$ adsorpsiyonu-desorpsiyonu, FTIR, SEM-EDS ve $\mathrm{NH}_{3}$-TPD ile karakterize edilmiştir. $\mathrm{NaOH}$ ile sepiyolitin modifikasyonu, sepiyolitin önemli miktarda desilikasyonuna ve dekatyonizasyonuna neden olmuştur. Sepiyolitin alkali muamelesi ile silisyum ve magnezyum çözünmesi sonucu sepiyolitin ortalama gözenek çapında artış ve yüzey alanında $187.8 \mathrm{~m}^{2} \mathrm{~g}^{-1}$ 'den $7.1 \mathrm{~m}^{2} \mathrm{~g}^{-1}$ ' a azalma belirlenmiştir. Ayrıca, zayıf ve orta asit merkezleri azalırken, güçlü asit merkezleri artmıştır. SP ile maksimum As(III) ve As(V) ayrımı pH=1.5'de sağlanmış olup, değerler yaklaşık olarak sıra ile $8.9 \mathrm{mg} \mathrm{g}^{-1}$ ve $26.8 \mathrm{mg} \mathrm{g}^{-1}$ 'dır. Na-SP örneklerinde maksimum As(III) ve As(V) ayrımı pH=5.0'de sağlanmış olup, onların miktarı ise sıra ile $46.7 \mathrm{mg} \mathrm{g}^{-1}$ ve $35.9 \mathrm{mg} \mathrm{g}^{-1}$ dır. Doğal sepiyolitin maksimum Mn(II) uzaklaştırma miktarı ise $5.2 \mathrm{mg} \mathrm{g}^{-1}$ 'dır. Sepiyolitin $\mathrm{NaOH}$ ile modifikasyonu ile arsenik adsorpsiyon kapasitesi dört kata kadar artmış olup, bu değer demir içeren sepiyolit örnekleri ve bimetalik oksitler ile karşılaştırılabilirdir. Langmuir izotermleri SP ile As(V) ve NaSP ile As(III) ayrımı sonuçlarına uyumlu olmasına karşılık Freundlich izoterm modeli SP ile Mn(II) ve Na-SP ile As(V) uzaklaştırmasında uygunluk göstermiştir. Doğal ve modifiye edilmiş sepiyolit ile arsenik ve mangan adsorpsiyonu için kaydırılmış ikinci mertebeden kinetik model iyi uyum sağlamaktadır.

Anahtar Kelimeler: Sepiyolit, mangan, arsenik, adsorpsiyon, $\mathrm{NaOH}$ ile muamele

\section{The Adsorptive Removal of Arsenic and Manganese from Aqueous Solution by Natural and Modified Sepiolite}

\author{
*1 Ayten Ateş, ${ }^{2}$ Gökhan Yaşar
}

${ }^{1}$ Cumhuriyet University, Engineering Faculty, Department of Chemical Engineering, 58140 Sivas, Turkey,aytates@gmail.com. ${ }^{2}$ Cumhuriyet University, Engineering Faculty, Department of Chemical Engineering,58140 Sivas, Turkey,gkhysr40@ gmail.com

\begin{abstract}
The natural sepiolite clay mineral was obtained from General Directorate of Mineral Research and Exploration (MTA) of Turkey and modified with $2.5 \mathrm{M}$ of $\mathrm{NaOH}$. The natural (SP) and modified (Na-SP) sepiolite samples were characterized by XRD, $\mathrm{N}_{2}$ adsorption-desorption, FTIR, SEM-EDS and $\mathrm{NH}_{3}$-TPD. The treatment of the sepiolite with $\mathrm{NaOH}$ led to a significant desilication and decationization of the SP. The alkali treatment with $\mathrm{NaOH}$ caused solution of silicon and cations, resulting in an increase in its average pore diameter and a decrease in its surface area from $187.8 \mathrm{~m}^{2} \mathrm{~g}^{-1}$ to $7.1 \mathrm{~m}^{2} \mathrm{~g}^{-1}$. In addition, a number of weak and medium acid centres of SP was decreased while a number of strong acid centres was increased. The maximum $\mathrm{As}(\mathrm{III})$ and $\mathrm{As}(\mathrm{V})$ removal with the $\mathrm{SP}$ was achieved at an initial $\mathrm{pH}$ of 1.5 , respectively; ca. $8.9 \mathrm{mg} \mathrm{g}^{-1}$ and $26.8 \mathrm{mg} \mathrm{g}^{-1}$. The

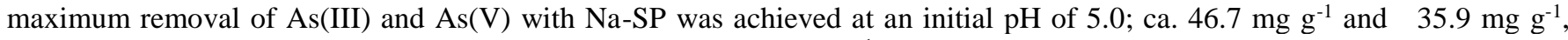
respectively. The maximum $\mathrm{Mn}(\mathrm{II})$ removal with $\mathrm{SP}$ was $5.2 \mathrm{mg} \mathrm{g}^{-1}$. Treatment of SP with $\mathrm{NaOH}$ increased its the arsenic
\end{abstract}

*Sorumlu Yazar: Cumhuriyet Üniversitesi, Mühendislik Fakültesi, Kimya Mühendisliği Bölümü, 58140 Sivas, Türkiye, aytates@gmail.com 
adsorption capacity up to four times, which is comparable to iron-containing sepiolite samples and bimetallic oxides. While the Langmuir isotherm fitted well with results obtained from the As(V) with SP and As(III) with Na-SP, the Freundlich isotherm model was more appropriate for the results obtained from As(V) with Na-SP and from Mn(II) of SP. The pseudo-second-order kinetic model for the adsorption of arsenic and manganese on natural and modified sepiolite fitted well.

Keywords: Sepiolite, manganese, arsenic, adsorption, tretament with $\mathrm{NaOH}$

\section{GíRiş}

Doğal su kaynaklarında bulunan arsenik kirliliği problemi farklı alanlarda araştırmacılarının ilgisini çekmektedir. Dünya çapında çoğu bölgelerde yer altı sularında arsenik, $\mathrm{As}(\mathrm{V})$ ve As(III) değerlikle bulunmaktadır. Arsenik zehirlenmesi Japonya, Çin, Meksika, Arjantin, Hindistan ve Amerika Birleşik Devletleri (ABD) gibi ülkelerde rapor edilmektedir [1], [2]. Dünya Sağlık Organizasyonu (WHO) içme sularında arsenik için maksimum kirlenme düzeyini 10 $\mu \mathrm{g} \mathrm{L}^{-1}$ değere indirgenmesini tavsiye etmektedir. Bu nedenle, endüstriyel atıklardan ya da içme sularından arsenik ayrımı için yeni malzemelerin ve düşük maliyetli alternatiflerinin geliştirilmesi ya da mevcut yöntemlerin iyileştirilmesi gerekmektedir [3].

Mangan yer kabuğunda bol miktarda bulunmaktadır. İçme sularında manganın varlığı ise, pirolusit $\left(\mathrm{MnO}_{2}\right)$ ve mangan bromid $\left(\mathrm{MnBr}_{2}\right)$ minerallerinin su kaynaklarına çözünmesinin bir sonucudur. Türkiye'nin Sivas bölgesinde, $\mathrm{MnO}_{2}$ ve $\mathrm{MnBr}_{2}$ kayaçlarının içme suyuna çözünmesi sonucu, iklim koşullarına bağlı olarak, içme sularında mangan derişimi maksimum kirlenme derişimine ulaşmaktadır. Ayrıca, mangan minerali galvanik, metal kaplama, metalürjik kimyasal üretim, madencilik ve pil imalatı gibi çeşitli endüstriyel kaynaklardan da gelebilmektedir. Türkiye'de içme sularında izin verilen $\mathrm{Mn}(\mathrm{II})^{\prime}$ in maksimum miktarı $0.1 \mathrm{mg} \mathrm{L} \mathrm{L}^{-1}$ iken ABD Çevre Koruma Ajansı (EPA)'nın izin verdiği derişim daha düşük olup, $0.05 \mathrm{mg} \mathrm{L}^{-1}$ 'dir. Sağlık yönetmeliklerinin bir sonucu olarak, içme sularında manganın derişim düzeyinin azaltılması zorunlu olmaktadır. $\mathrm{Bu}$ nedenle, siralanan konvansiyonel yöntemler uygulanmaktadır: Membran filitrasyon [4], [5], kimyasal çöktürme [5] ve silika [6] ve aktif karbon [7] ile iyon değişimidir [8]. Ayrıca, uygun bir adsorbent seçildiğinde ya da tasarlandığında, ekonomik ve kolay işletime sahip olan adsorpsiyon prosesi önemli bir alternatif olabilmektedir. Zeolitler, sepiyolit, kitosan ve kil gibi bazı doğal malzemeler düşük maliyetli adsorbentlere alternatif olarak göz önüne alınmaktadır [9]. Doğal malzemeler arasından, sepiyolit, $\left(\mathrm{Si}_{12}\right)\left(\mathrm{Mg}_{8}\right) \mathrm{O}_{30}(\mathrm{OH})_{4}\left(\mathrm{OH}_{2}\right)_{4} \cdot 8 \mathrm{H}_{2} \mathrm{O}$ birim hücre formülüne sahip, mikro fiber yapılı bir magnezyum hidrosilikattir [10], [11]. Ayrıca, sepiyolit yüksek yüzey alanına ve yüksek kimyasal ve mekanik kararlılığa sahiptir [12]. Sepiyolitin karakteristik özellikleri, organik ve inorganik iyonları adsorplamakta adsorbent olarak kullanımına imkan verebilmektedir. Sepiyolitin genel yapısı mikro fiber yönde büyüyen blok ve tünellerin birbirinden ayrılmasıyla oluşmaktadır. Her bir blok, merkezde yer alan oktahedral magnezyum tabakaya bitişik iki tetrahedral silika tabakasından oluşmaktadır. Ancak silika tabakalar sürekli olmayıp, silika tabakaların ters çevrilmesi yapısal tünellere neden olmaktadır. Sepiyolitin kozmetik, seramik, deterjan, kağıt ve boya gibi endüstriyel alanlarda da uygulamaları, malzemenin moleküler büyüklükteki kanallarının ve yüksek yüzey alanının ( > $200 \mathrm{~m}^{2} / \mathrm{g}$ ) bir sonucu olabilmektedir [13]. Sepiyolit, ağır metalleri $\left(\mathrm{Cu}^{+2}, \mathrm{Zn}^{+2}, \mathrm{Cd}^{+2}, \mathrm{Co}^{+2}, \mathrm{~Pb}^{+2}, \mathrm{Sr}^{+2}\right.$ ve $\mathrm{Cr}^{+6}$ ) [14]-[22] içeren atık su arıtımı için yüksek adsorpsiyon kapasitesine sahiptir. Fakat doğal sepiyolit ile içme sularından arsenik ve mangan ayrımı için sadece birkaç çalışma bulunmaktadır [19], [23], [24].

$\mathrm{Bu}$ çalışmanın amacı adsorpsiyon ile sulu çözeltilerden $\mathrm{Mn}(\mathrm{II}), \mathrm{As}(\mathrm{III})$ ve As(V) türlerini ayırmak için doğal ve modifiye edilmiş sepiyolitin kapasitesinin belirlenmesidir. Doğal ve modifiye edilmiş sepiyolitin adsorpsiyon kapasitesi üzerine başlangıç pH değerinin, başlangıç metal derişiminin ve temas süresinin etkisi incelenmiștir. Doğal ve modifiye edilmiş sepiyolitin kimyasal bileşimi, morfolojisi, faz bileşimi, spesifik yüzey alanı ve gözenek hacmi belirlenmiştir.

\section{MALZEME VE YÖNTEM}

\subsection{Malzemeler}

Doğal sepiyolit (SP) Türkiye'nin Maden Tetkik ve Arama (MTA) kurumundan sağlanmıştır. Sepiyolit ilk olarak bilyeli değirmen ile öğütülmüş ve elek ile parçacık boyutu $0.25-0.5 \mathrm{~mm}$ aralığına ayarlanmış ve $120{ }^{\circ} \mathrm{C}^{\prime} \mathrm{de}$ kurutulmuştur. Sepiyolitin $\mathrm{Na}$ formu, $80{ }^{\circ} \mathrm{C}$ 'de $2.5 \mathrm{M}$ $\mathrm{NaOH}$ 'in $250 \mathrm{~cm}^{3}$ ile $10 \mathrm{~g}$ doğal sepiyolitin Heidolph MR 3001 manyetik karıştırıcı ile 200 rpm karıştırma hızında $60 \mathrm{dk}$ süre ile muamelesi ile hazırlanmıştır. Y1kama ve kurutma sonrasında örnek 2 saat süre ile $500{ }^{\circ} \mathrm{C}$ 'de hava atmosferinde kalsine edilmiş ve böylece $\mathrm{Na}$ içeren sepiyolit (Na-SP) üretilmiştir.

Adsorpsiyon çalışmalarında arsenik ve manganın $1000 \mathrm{mg}$ $\mathrm{L}^{-1}$ başlangıç çözeltiler kullanılmıştır. As(V) çözeltisi, \% 2 $\mathrm{HNO}_{3}$ 'de çözülmüş $\mathrm{As}_{2} \mathrm{O}_{3}$ (Fluka, 39436), As(III) çözeltisi $0.5 \mathrm{M} \mathrm{HNO}_{3}$ ' de çözülmüş $\mathrm{H}_{3} \mathrm{AsO}_{4}$ (Merck, 1.19773.0500) ve $\mathrm{Mn}$ (II) çözeltisi $\mathrm{Mn}\left(\mathrm{NO}_{3}\right)_{2} .4 \mathrm{H}_{2} \mathrm{O}$ (Merck, A369440) tuzu ile hazırlanmıştır. Kesikli adsorpsiyon deneylerinde istenen derişime çözeltiler stok metal çözeltilerinin deiyonize su kullanılarak seyreltilmesi ile hazırlanmıştır.

\section{2. Örneklerin Karakterizasyonu}

SP ve Na-SP örneklerinin kimyasal bileşimi Taramalı Elektron Mikroskobu (SEM) (JEOL/ JSM-6610) üzerine 
yerleştirilmiş Enerji Dağılımlı X-Işını Spektroskopisi (EDS) (OXFORD INSTRUMENTS INCA X-Act / 51-ADD0013) kullanılarak analiz edilmiştir.

SP ve Na-SP örneklerinin morfolojisi SEM (SEM) (JEOL/ JSM-6610) ile görüntülenmiştir.

Örneklerin X-Işını Kırınımı (XRD) mono kromatografik olmayan $\mathrm{Cu} \mathrm{K} \alpha 1$-radyasyonlu $(40 \mathrm{kV}, 40 \mathrm{~mA}, \lambda=1.5 \AA)$ Rigaku SmartLab X-ray diffraktometer ile belirlenmiştir. Tarama aralığ $12 \theta=5-65^{\circ}$ dir.

Örneklerin spesifik yüzey alanı ve gözenek hacimleri -196 ${ }^{\circ} \mathrm{C}$ 'de $\mathrm{N}_{2}$ adsorpsiyonu- desorpsiyonu (AUTOSORB 1C) yöntemi kullanılarak analiz edilmiştir. Adsorpsiyon öncesinde, örnekler oda sıcaklığında 66.6 Pa basınca kadar vakum uygulanmış ve sonra $250^{\circ} \mathrm{C}$ 'e örnek hücresi isıtılmış ve $1.3 \mathrm{~Pa}$ basınca ulaşıncaya kadar vakum uygulanmıştır. Yüzey alanı, toplam gözenek hacmi ve mikro gözenek hacmi sıra ile çok noktalı BET, t-plot ve DR (DubininRadushkevic) yöntemleri ile belirlenmiştir.

Infrared absorpsiyon ölçümleri Fourier Transform Infrared (FTIR) spektrofotometresi (Bruker Optics- Alpha) ile ölçülmüsstür. FTIR spektrum elmas kristalli tek sekmeli ATR kullanılarak $650-4000 \mathrm{~cm}^{-1}$ dalga boyu aralığında ölçülmüştür. Örneklerin FTIR spektrumu 128 taramanın ortalamasıdır ve ölçümlerde kullanılan spektrum çözünürlüğü ise $4 \mathrm{~cm}^{-1}$ dir.

Doğal ve modifiye edilmiş sepiyolitin yüzey asitliğini belirlemek için amonyak ile sıcaklık programlı desorpsiyon $\left(\mathrm{NH}_{3}\right.$-TPD) Autochem II-2920 (Micromeritics) cihaz1 kullanılarak belirlenmiştir. Örnekler $50{ }^{\circ} \mathrm{C}$ 'de helyumda \% 15 (v./v.) $\mathrm{NH}_{3}{ }^{\prime}$ in akışı ile doyurulmuş ve sonra adsorplanmış amonyak saf helyumun $25 \mathrm{~cm}^{3} \mathrm{dk}^{-1}$ akış hızı ile $10 \mathrm{~K} \mathrm{dk}^{-1}$ ısıtma hızı ile $900{ }^{\circ} \mathrm{C}$ 'e kadar 1sıtma ile desorbe edilmiştir.

\subsection{Adsorpsiyon Deneyleri}

Kesikli adsorpsiyon deneyleri $200 \mathrm{rpm}$ sabit karıştırma hızında $25{ }^{\circ} \mathrm{C}$ 'de manyetik bir karıştıııcı (IKA-RT10) kullanılarak cam erlenlerde $(0.1 \quad$ L) gerçekleştirilmiştir. Kinetik çalışmalarda, manganın $25-250 \mathrm{mg} \mathrm{L}^{-1}$ derişim aralığ 1 ve arsenik örneklerinin $25-100 \mathrm{mg} \mathrm{L}^{-1}$ derişim aralığında zamanın farklı periyotlarında deneyler gerçekleş̧tirilmiştir. $\mathrm{pH}$ değişimi ile $\mathrm{Mn}(\mathrm{II})$ 'in çökmesi nedeniyle çözeltinin doğal $\mathrm{pH}(\mathrm{pH}=\sim 6.0)$ 'ında, deneyler gerçekleştirilmiştir. SP ve Na-SP ile arsenik adsorpsiyonu pH'in 1.5- 9.0 aralığında gerçekleştirilmiştir. Adsorpsiyon kapasitesine $\mathrm{pH}^{\prime} 1 \mathrm{n}$ etkisi incelemesinde $1 \mathrm{~g} \mathrm{~L}^{-1}$ adsorbent miktarı, $25^{\circ} \mathrm{C}^{\prime}$ de ve $100 \mathrm{mg} \mathrm{L}^{-1}$ başlangıç arsenik derişimi ile 8 saat adsorpsiyon süresi ile gerçekleştirilmiştir. As(III, V) çözeltilerinin başlangıç $\mathrm{pH}^{\prime} \mathrm{HCl}_{\mathrm{HC}} \mathrm{NaOH}$ çözeltileri ile Chebios $640 \mathrm{Lab} \mathrm{pH}$ metre kullanılarak ayarlanmıştır. Arsenik ve manganın adsorpsiyon denge süresinin belirlenmesi, farklı adsorpsiyon sürelerinde farklı arsenik ve mangan derişimlerinde $25^{\circ} \mathrm{C}^{\prime}$ de $1 \mathrm{~g} \mathrm{~L}^{-1}$ adsorbent miktarı ile gerçekleştirilmiştir. Adsorpsiyon sonrasında, çözelti karışımdan katı ve sıvıyı ayırmak için 5000 rpm'de $5 \mathrm{dk}$ santrifüj (Hettich Zantrifugen, Universal 16A) edilmiştir. Adsorpsiyon öncesi başlangıçta ve adsorpsiyon sonrası sıvıda kalan arsenik ve mangan derişimleri Atomik Absorpsiyon Spektrofotometresi (AAS) (GBC A4382) ile ölçülmüsşür. Sağlanan tüm sonuçlar iki deneysel çalışmanın ortalamasidır.

Arsenik ve manganın adsorpsiyon kapasitesi $\left(\mathrm{q}_{\mathrm{e}}, \mathrm{mg} \mathrm{g}^{-1}\right)$ ve ayrılma yüzdesi (\%) denklem 2.1 ve 2.2 ile belirlenmiştir.

$\mathrm{qe}=\frac{(\mathrm{Co}-\mathrm{Ce}) \mathrm{V}}{\mathrm{m}}$

Ayrılma etkinliği $(\% \mathrm{R})=\frac{(\mathrm{Co}-\mathrm{Ce})}{\mathrm{Co}} \times 100$

Burada Co ve Ce sıra ile arsenik ya da manganın başlangıçta ve adsorpsiyon sonrası $\left(\mathrm{mg} \mathrm{L}^{-1}\right)$, derişimlerini ve $\mathrm{m}$ ise adsorpsiyon deneylerinde kullanılan adsorbentin $\mathrm{g}$ miktarıdır. Doğal ve modifiye edilmiş sepiyolitler için denge verileri önceki çalı̧̧malarda rapor edildiği gibi [25], Langmuir ve Freundlich modelleri ile fit edilmiştir.

Doğal ve modifiye edilmiş sepiyolit ile, arsenik türlerinin ve manganın doğa ve mekanizmasını incelemek için, kaydırılmış birinci mertebe, kaydırılmış ikinci mertebe ve partikül içi difüzyon modelleri deneysel verilere uygulanmıştır [26]. Bu amaç için, sıvı filimde difüzyon direncini kırmak için adsorbentler çözeltinin yüksek karıştırma hızına neden olan 1500 rpm'de IKA ( Eurostar High speed) mekanik karıştırıcı ile karıştırılmıştır. Çözeltiden belli zaman aralıklarında örnekler alınarak AAS'de analiz edilmiştir.

\section{Adsorpsiyon kinetik denklemleri}

The Lagergren kaydırılmış birinci mertebe kinetik model [27] aşağıdaki gibi verilmiştir.

$\log \left(q_{e}-q_{t}\right)=\log q_{e}-\frac{k_{1}}{2.303} t$

Burada $\mathrm{q}_{\mathrm{t}}(\mathrm{mg} / \mathrm{g})$ belirli bir zamanda adsorbentte adsorplanmış arsenik ya da manganın miktarı ve $\mathrm{k}_{1}\left(\mathrm{dk}^{-1}\right)$ kaydırılmış 1. mertebeden kinetik model için hız sabittir.

Kaydırılmış ikinci mertebeden kinetik için denklem [27] aşă̆ıdaki gibidir:

$\frac{d q_{t}}{d t}=K\left(q_{e}-q_{t}\right)^{2}$

Burada $\mathrm{q}_{\mathrm{e}}$ ve $\mathrm{q}_{\mathrm{t}}$ sira ile dengede ve herhangi bir $\mathrm{t}$ anında adsorbentin birim kütlesi başına adsorplanmış arsenik ya da manganın miktarıdır.

Denklem (2.4)'in lineer şekli aşağıdaki gibidir: 
$\frac{t}{q_{t}}=\frac{1}{K q_{e}{ }^{2}}+\frac{1}{q_{e}} t$

Partikül içi difüzyon modeli aşağıdaki gibi tanımlanabilir:

$q_{t}=k_{p} t^{\frac{1}{2}}+C$

Burada $\mathrm{k}_{\mathrm{p}}$ partikül içi difüzyon hız sabiti $\left(\mathrm{mg} \mathrm{g}^{-1} \mathrm{~min}^{-0.5}\right)$ ve $\mathrm{C}$ ise adsorpsiyon sabitidir.

\section{Adsorpsiyon termodinamiğ $i$}

Mangan ve arseniğin adsorpsiyonu için Gibbs serbest enerji değişimi $\left(\Delta \mathrm{G}^{\circ}\right)$, entalpi değişimi $\left(\Delta \mathrm{H}^{\circ}\right)$ ve entropi değişimi $\left(\Delta \mathrm{S}^{\circ}\right)$ belirlenmiştir [28]. Kimyasal bir olayın olup olmayacağını belirlemede $\Delta \mathrm{G}^{\circ}$ 'in değeri önemlidir ve aşağıdaki denklem ile hesaplanabilir:

$\Delta \mathrm{G}=-\mathrm{RT} \operatorname{lnKc}$

Burada Kc ((adsorbentte adsorbatın miktarı)/(çözeltide adsorbatın miktarı)) dağılım katsayısıdır [29], [30].

Entalpi değişimi ve entropi değişimi aşağıdaki denklemden hesaplanabilir.

$$
\ln K_{c}=\frac{\Delta S}{R}-\frac{\Delta H}{R T}
$$

\section{SONUÇLAR VE TARTIŞMALAR}

\section{1. Örneklerin Kimyasal Bileşimi}

Doğal ve muamele edilmiş sepiyolitlerin SEM-EDS analiz sonuçları Tablo 1'de gösterilmiştir. Sepiyolit minerali çoğunlukla $\mathrm{Si}^{+4}, \mathrm{Mg}^{+2}$ ve $\mathrm{Al}^{+3}$ olmak üzere $\mathrm{Fe}^{+3}, \mathrm{Ca}^{+2}, \mathrm{~K}^{+}$ve $\mathrm{Ti}^{+4}$ 'in eser miktarda varlığından oluşmaktadır. $\mathrm{NaOH}$ ile SP'in muamelesi SP'in önemli miktarda desilikasyonuna neden olmaktadır. Ayrıca, $\mathrm{Mg}^{+2}$ in önemli bir miktarı yapıdan ayrılmasına ek olarak, $\mathrm{Na}$ içeriğinde de önemli miktarda artış analiz edilmiştir.

Tablo 1. Doğal ve $\mathrm{NaOH}$ ile muamele edilmiş sepiyolitin EDS ile belirlenmiş kütlesel kimyasal bileşimi

\begin{tabular}{|l|c|c|c|c|c|c|c|c|}
\hline Örnek & $\mathrm{Mg}$ & $\mathrm{Al}$ & $\mathrm{Si}$ & $\mathrm{K}$ & $\mathrm{Na}$ & $\mathrm{Ca}$ & $\mathrm{Ti}$ & $\mathrm{Fe}$ \\
\hline $\mathrm{SP}$ & 20.1 & 9.4 & 66.9 & 0.4 & - & 1.0 & 0.2 & 1.6 \\
\hline $\mathrm{Na}-\mathrm{SP}$ & 14.8 & 4.2 & 27.1 & 0.6 & 46.8 & 1.8 & - & 4.4 \\
\hline
\end{tabular}

\section{2. Örneklerin XRD Analiz Sonuçları}

Doğal ve $\mathrm{NaOH}$ ile muamele edilmiş sepiyolitin XRD analiz sonucu Şekil 1'de gösterilmiştir. Brindley [31]'in sepiyolit için yayınladığı rapora göre ve MDI-Jade 6 programı ile yapilan faz analizine göre $2 \theta^{\prime}$ 'n $7.3,11.837,13.144,17.688$, 19,712 , 20.590, 23.707, 25.208, 26.426, 27.857, 29.257, $34.235,35.022,36.665,39.800,43.715,60.986$ ve $61.706^{\circ}$ piklerinin varlığ 1 ham maddenin sepiyolit $\left(\mathrm{Mg}_{4} \mathrm{Si}_{6} \mathrm{O}_{15}(\mathrm{OH})_{2} \bullet 6\left(\mathrm{H}_{2} \mathrm{O}\right)\right.$, pdf no: 13-0595) faz bileşime sahip olduğunu göstermiştir. $\mathrm{NaOH}$ ile muameleden sonra, malzemenin sepiyolit fazı azalırken, yapıda sodyum magnezyum silikat türlerinin $\left(\mathrm{Na}_{1.8} \mathrm{Mg}_{0.9} \mathrm{Si}_{1.1} \mathrm{O}_{4}\right.$ (47-1497), $\mathrm{Na}_{2} \mathrm{MgSiO}_{4}$ (47-1499), ve $\mathrm{Na}_{4} \mathrm{Mg}_{2} \mathrm{Si}_{3} \mathrm{O}_{10} \quad$ (33-1265)) oluşumu MDI- Jade 6 programı ile yapılan faz analizi ile belirlenmiştir. Ayrıca, 20'ın 7.3, 19,712, 20.590, 20.59, $35.022^{\circ}$ 'deki pikleri kaybolmuş olup, bu $\mathrm{NaOH}$ ile muamele ile sepiyolitin desilikasyonun varlığının bir sonucu olmaktadir.

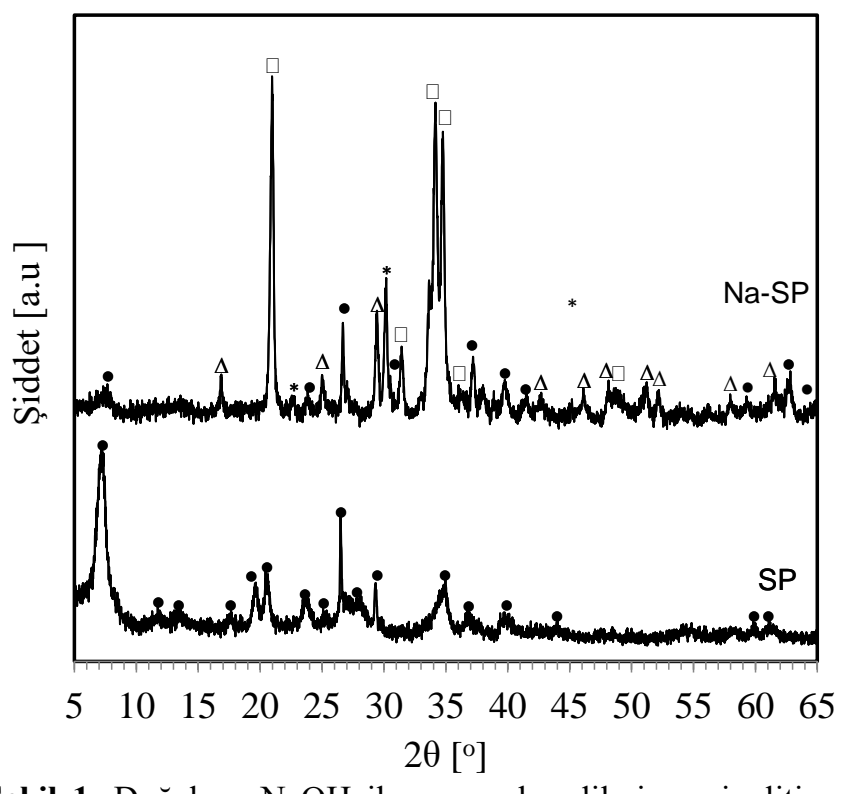

Şekil 1. Doğal ve $\mathrm{NaOH}$ ile muamele edilmiş sepiyolitin XRD analiz sonuçları: Semboller: Sepiyolit( $\bullet)$, Sodyum magnezyum silikat (( $\mathrm{Na}_{1.8} \mathrm{Mg}_{0.9} \mathrm{Si}_{1.1} \mathrm{O}_{4}(\Delta), \mathrm{Na}_{2} \mathrm{MgSiO}_{4}\left(^{*}\right)$, ve $\left.\mathrm{Na}_{4} \mathrm{Mg}_{2} \mathrm{Si}_{3} \mathrm{O}_{10}(\square)\right)$.

\section{3. Örneklerin SEM Görüntüleri}

SP ve Na-SP örneklerinin SEM görüntüleri Şekil 2'de gösterilmiştir. $\mathrm{NaOH}$ ile muamele sonrası, parçacıklar düzensizleşerek aglomerasyona uğramıştır. XRD verilerinde de görüldüğü gibi, desilikasyonun varlığ sepiyolit yapısının bozulmasına sebep olabilmektedir.

Benzer olarak, Li ve arkadaşları [32], farklı derişimlerde $\mathrm{NaOH}$ ile HZSM-5 zeolitini muamele ettiklerinde, $1.0 \mathrm{M}$ $\mathrm{NaOH}$ derişiminde, HZSM-5 yapısının düzensizleştiğini, partiküllerin eriyerek düzensiz bir yapı gösterdiğini SEM sonuçları ile göstermişlerdir.

Ayrıca, HZSM-5 örneğinin bağıl kristal bileşiminde \% 75 oranında azalmanın desilikasyonun bir sonucu olduğu rapor edilmiştir. Melian-Cabrera ve arkadaşları, demir ile iyon değişmiş ZSM-5 zeolitlerin $\mathrm{NaOH}$ ile muamelesinin etkisini incelemiş ve $30 \mathrm{dk} 0.2 \mathrm{M} \mathrm{NaOH}$ ile liçing işleminin $\mathrm{Fe}$ ZSM-5 kristal yapısında kırılmalara neden olduğunu rapor etmişlerdir [33], [34]. 

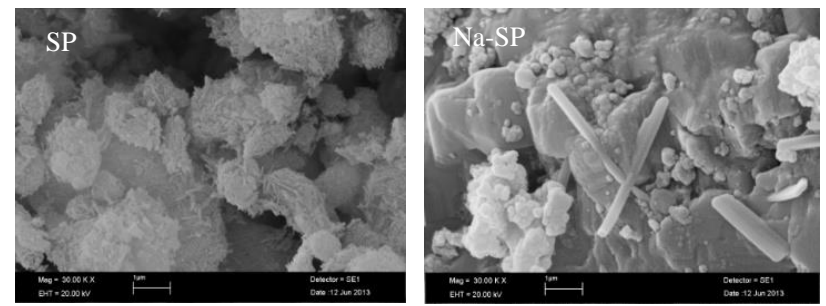

Şekil 2. Doğal ve $\mathrm{NaOH}$ ile muamele edilmiş sepiyolitin SEM görünümleri

\section{4. Örneklerin Yüzey Alanı ve Gözenek Boyut Dağılımı}

Doğal ve modifiye edilmiş sepiyolitlerin $\mathrm{N}_{2}$ adsorpsiyondesorpsiyon izotermleri ve gözenek boyut dağılımları Şekil 3'de gösterilmiştir. Ayrıca, izotermlerden hesaplanmış yüzey alanı ve gözenek özellikleri Tablo 2'de listelenmiştir. SP'in izotermi IUPAC sinıflandırmasına göre [35] Tip I izotermine uymakta olup, bu mikro gözenekli malzemelerin özelliğidir. SP ve Na-SP'ın yüzey alanı sıra ile $187.8 \mathrm{~m}^{2} \mathrm{~g}^{-1}$ ve $7.09 \mathrm{~m}^{2} \mathrm{~g}^{-1}$ olup, $\mathrm{NaOH}$ ile muamele ile desilikasyon ve dekatyonizasyon ile gözenek çapının 194 A’dan 264 A’e artışı ile mikro gözenekler mezo gözeneklere dönüşmesine neden olmasının bir sonucudur.
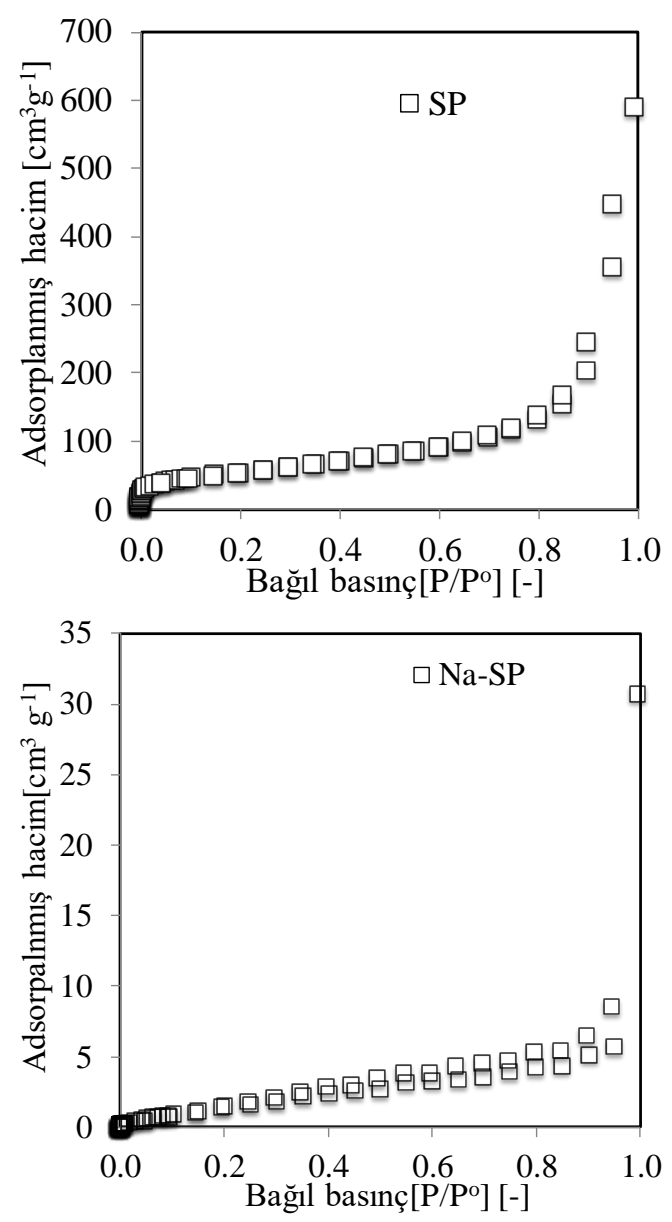

Tablo 2. Doğal ve modifiye edilmiş sepiyolit örneklerinin yüzey alanı ve gözenek özellikleri

\begin{tabular}{|c|c|c|c|c|}
\hline Örnek & $\begin{array}{c}\text { SA } \\
\left(\mathrm{m}^{2} \mathrm{~g}^{-1}\right)^{\mathrm{a}}\end{array}$ & $\begin{array}{c}\mathrm{V}_{\mathrm{T}} \\
\left(\mathrm{cm}^{3} \mathrm{~g}^{-1}\right)^{\mathrm{b}}\end{array}$ & $\begin{array}{c}\mathrm{V}_{\mathrm{MP}} \\
\left(\mathrm{cm}^{3} \mathrm{~g}^{-1}\right)^{\mathrm{c}}\end{array}$ & $\begin{array}{c}\mathrm{d} \\
(\AA)^{\mathrm{d}}\end{array}$ \\
\hline SP & 187.8 & 0.91 & $5.66 \times 10^{-2}$ & 194 \\
\hline Na-NSP & 7.1 & 0.04 & $5.4 \times 10^{-4}$ & 268 \\
\hline
\end{tabular}

\section{5. Örneklerin FTIR Sonuçları}

SP ve Na-SP örneklerinin FTIR spektrumu Şekil 4'de gösterilmiştir. Örneklerin FTIR spektrumu üç bölgede incelenmiştir [36], [37]. $4000-3000 \mathrm{~cm}^{-1}$ aralığındaki pikler $\mathrm{Mg}-\mathrm{OH}$ grubunun titreşimlerini $\left(3690 \mathrm{~cm}^{-1}\right)$, su pikini $\left(3568 \mathrm{~cm}^{-1}\right)$ ve sepiyolit suyunu $\left(3422 \mathrm{~cm}^{-1}\right)$ göstermekte olup, bu bantlar EDS ve XRD sonuçlarında açıkça görüldüğü gibi $\mathrm{NaOH}$ ile önemli miktarda uzaklaşan silisyumun sonucu $\mathrm{OH}^{-}$gruplarının yapıdan uzaklaşmasının bir sonucu olabilmektedir.

$1671 \mathrm{~cm}^{-1}$ 'de bant örnekteki suyu göstermekte olup, $\mathrm{NaOH}$ ile muamele ile desilikasyonun bir sonucu olarak kaybolmaktadir.
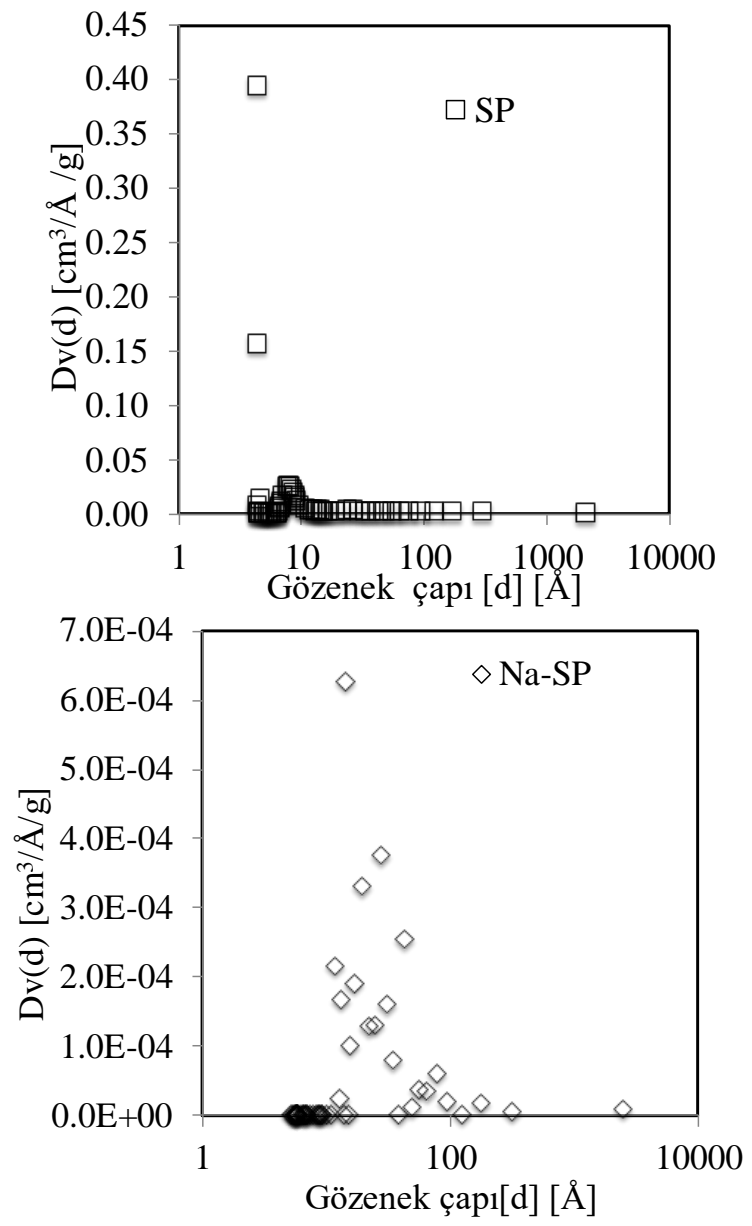

Şekil 3. SP ve Na-SP'in $\mathrm{N}_{2}$ adsorpsiyonu- desorpsiyonu izotermi ve gözenek boyut dağılımı. 
1200-650 $\mathrm{cm}^{-1}$ aralığında ki bantlar silika ile ilişkilidir. $1016 \mathrm{~cm}^{-1 '}$ deki pik Si-O-Si titreşimleri ile ilişkili olup $\mathrm{NaOH}$ ile muamele, desilikasyonun bir sonucu olarak hem dalga boyunu $1016 \mathrm{~cm}^{-1}$ 'den $876 \mathrm{~cm}^{-1}$ 'e kaydırmakta hem de pikin şiddeti önemli ölçüde azaltmıştır

1215 ve $980 \mathrm{~cm}^{-1 / d e}$ pikler Si-O bantlarını göstermekte olup, bunlar $\mathrm{NaOH}$ ile muamele ile, desilikasyonun bir sonucu kaybolmaktadır. $690 \mathrm{~cm}^{-1}$, deki pik $\mathrm{Mg}-\mathrm{OH}$ bağ titreşimine karşılık gelen pik olup, alkali muamele ile $\mathrm{Mg}$ 'in derişiminin azalmasının bir sonucu olarak kaybolmuştur.
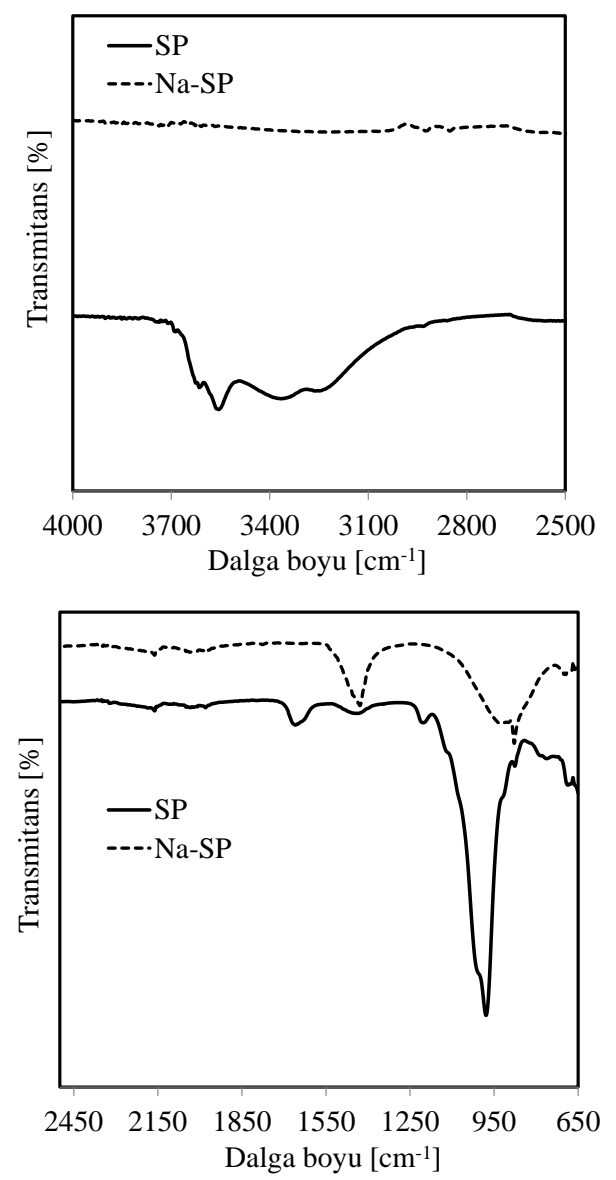

Şekil 4. Doğal ve modifiye edilmiş sepiyolitin FTIR spektrumu

\section{6. Örneklerin $\mathrm{NH}_{3}$-TPD sonuçları}

Sepiyolitin asitliği üzerine desilikasyonun etkisi $\mathrm{NH}_{3}-\mathrm{TPD}$ ile incelenmiştir ve elde edilen sonuçlar Şekil 5'de gösterilmiştir. Sepiyolit yüzeyinden amonyak üç bölgede desorplanmaktadır. $\mathrm{NH}_{3}$-TPD profilinde, iki keskin desorpsiyon pikleri $100{ }^{\circ} \mathrm{C}$ ve $735{ }^{\circ} \mathrm{C}$ 'de ve $250{ }^{\circ} \mathrm{C}$ bölgesinde bir omuz gözlenmiştir. $100{ }^{\circ} \mathrm{C}$ 'deki pik ve $250^{\circ} \mathrm{C}$ bölgesindeki omuz sirayla zayıf asit merkezlerini ve Lewis asit merkezleri ile ilişkilidir [38], [39]. $500{ }^{\circ} \mathrm{C}$ 'den yüksek sıcaklıklarda pik güçlü asit merkezleri ile ilişkilidir.

$\mathrm{NaOH}$ ile muamele sonrası, SP yüzeyinde asit merkezlerinin dağılımı sodyum katyonları ile protonlarının değişimiyle önemli miktarda değişmektedir. SP'in $\mathrm{NaOH}$ ile muamelesi
$500{ }^{\circ} \mathrm{C}^{\prime}$ in üzerinde güçlü Brønsted asit merkezlerinin artışına sebep olurken, $500{ }^{\circ} \mathrm{C}$ 'in altında yer alan orta ya da zayıf Brønsted/Lewis asit merkezlerinde bir azalmaya sebep olmaktadir.

Desilikasyonun bir sonucu olarak orta ya da zayıf Brønsted/Lewis asit merkezlerinin kaybolmasına karşılık, güçlü asit merkezlerinin artışı sodyum magnezyum silikat türlerinin oluşumunun bir sonucu olmaktadır. Benzer sonuçlar doğal zeolitlerin $\mathrm{NaOH}$ ile muamelesi için rapor edilmiştir [25]. Sivas-Yavu bölgesinden sağlanmış doğal zeolitin $\mathrm{NaOH}$ ile muamele sonrası, $600{ }^{\circ} \mathrm{C}$ 'in altındaki amonyum desorpsiyon pikleri kaybolmuş ve $600{ }^{\circ} \mathrm{C}$ 'in üzerindeki amonyak desorpsiyon piki ise artmıştır.

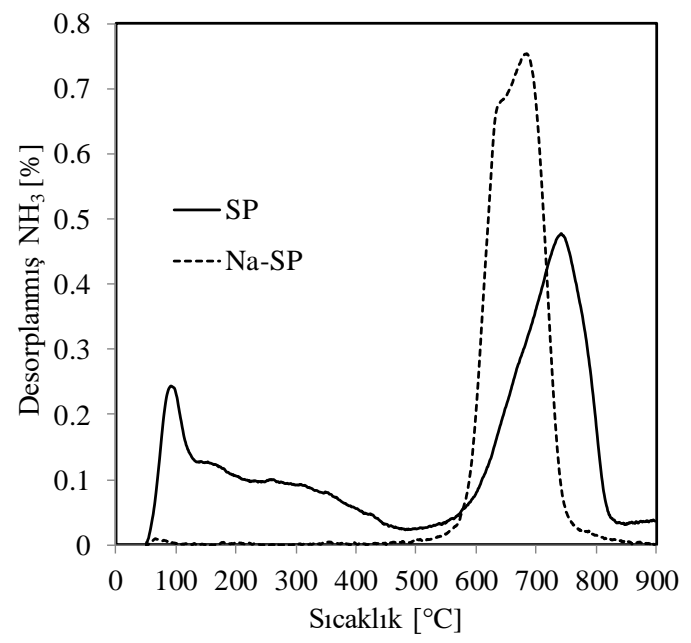

Şekil 5. Doğal ve modifiye edilmiş sepiyolitin $\mathrm{NH}_{3}-\mathrm{TPD}$ sonuçları

\subsection{Doğal ve Modifiye Edilmiş Sepiyolit ile Arseniğin ve Manganın Adsorpsiyonu}

\section{Başlangıç pH'ın Etkisi}

Arsenik adsorpsiyon çalışmalarında çok önemli faktörlerden birisi çözeltinin başlangıç pH'dır. Çözelti başlangıç pH'1 adsorbetin yüzey özeliklerini ve arseniğin moleküler yapısını etkilemektedir. Sepiyolitin adsorpsiyon kapasitesinin çözeltinin başlangıç $\mathrm{pH}$ 'i ile değişimi Tablo 3'de gösterilmiştir. SP ile As(III) ve As(V)'in maksimum adsorpsiyon kapasitesi $\mathrm{pH}=1.5$ 'de sağlanmıştır. Zhang vd.[40], pH'ın 1.5-5.0 aralığında, As (V) genellikle $\mathrm{H}_{2} \mathrm{AsO}_{4}{ }^{-}$ve $\mathrm{HAsO}_{4}{ }^{2-}$ olarak bulunduğunu ve adsorbentin ise pozitif olarak yüklendiğinden dolayı elektrostatik etkileşim meydana geldiğini rapor etmişlerdir. Fakat artan çözelti pH ile, yüzeydeki hidroksil grupları protonlarını kaybettikleri için, yüzey negatif yüklenmekte ve elektriksel itme nedeniyle adsorpsiyon kapasitesi azalabilmektedir. $\mathrm{As}(\mathrm{III})$ ise, $\mathrm{As}(\mathrm{V})$ 'e göre iyonik olmayan $\left(\mathrm{H}_{3} \mathrm{AsO}_{3}\right)$ türlere sahip olduğunda, As(III) adsorpsiyonu As(V)'den daha düşüktür. $\mathrm{NaOH}$ ile muamele edilmiş sepiyolit örneğinde ise, alkali muamele ile $\mathrm{OH}^{-}$grupları yapıdan uzaklaşmış olup, arsenik adsorpsiyon mekanizması, elektrostatik etkileşimden çok $\mathrm{Na}$ ile iyon değişimi ile 
gerçekleşebilmektedir. Benzer çalışmalar zeolitler için rapor edilmiş olup, zeolitlere sodyumun yüklenmesi, zeolitlerin diğer katyonlar ile yer değiştirmesini kolaylaştırdığı rapor edilmiştir [41]-[43]. Na-SP ile As(III) ve As(V)'in maksimum adsorpsiyon kapasitesi $\mathrm{pH}=5$ 'de sağlanmış olmas1, $\mathrm{NaOH}$ ile muamele ile yapida sodyum magnezyum silikat türlerinin oluşumu ve $\mathrm{OH}^{-}$gruplarının uzaklaşması ile yüzey yükünün değişmesinin bir sonucu olabilmektedir. Ayrıca, Na-SP'in yüksek adsorpsiyon kapsitesi ise, arsenik uzaklaştırılmasının hem elektriksel etkileşim ile hem de $\mathrm{Na}$ ile iyon değişiminin bir sonucu olabilmektedir.

Tablo 3. Doğal ve modifiye edilmiş sepiyolit ile As(III) ve $\mathrm{As}(\mathrm{V})^{\prime}$ 'in adsorpsiyon kapasitesi $\left(\mathrm{mg} \mathrm{g}^{-1}\right)$ üzerine $\mathrm{pH}$ 'ın etkisi $\left(\mathrm{Co}=100 \mathrm{mg} \mathrm{L}^{-1}, \mathrm{~T}=25^{\circ} \mathrm{C}\right.$, adsorpsiyon süresi: 8 saat, $\mathrm{m}_{\text {adsorbent }}=0.02 \mathrm{~g}$ ve Vçözelti $=20 \mathrm{~cm}^{3}$, karıştırma hızı: 200 rpm).

\begin{tabular}{rcccc}
\hline Örnek & \multicolumn{2}{c}{$\mathrm{SP}$} & \multicolumn{2}{c}{$\mathrm{Na}-\mathrm{SP}$} \\
\hline $\mathrm{pH}$ & $\mathrm{As}(\mathrm{III})$ & $\mathrm{As}(\mathrm{V})$ & $\mathrm{As}(\mathrm{III})$ & $\mathrm{As}(\mathrm{V})$ \\
\hline 1.5 & 8.92 & 26.84 & 5.68 & 5.07 \\
3.0 & - & 1.77 & 2.99 & 0.78 \\
5.0 & - & 3.48 & 46.70 & 35.96 \\
7.0 & 2.15 & 2.62 & - & 0.11 \\
9.0 & 2.05 & 1.45 & - & - \\
\hline
\end{tabular}

\section{Adsorpsiyon izoterm çalışmaları ve modelleme}

Adsorpsiyon süresi ile $\mathrm{SP}$ ve Na-SP'in adsorpsiyon kapasitesi değişimi Şekil 6'da gösterilmiștir. SP ve Na-SP ile As(V)'in denge süresi sirayla $120 \mathrm{dk}$ ve $480 \mathrm{dk}$ iken, As(III)'in denge süresi $180 \mathrm{dk}$ ve $480 \mathrm{dk}$ 'dır.

Adsorpsiyon izotermi, adsorpsiyon mekanizmasina ek olarak adsorbentin adsorpsiyon kapasitesi hakkında da bilgi vermektedir [44]. SP ve Na-SP ile As(III,V)'in adsorpsiyonu için, Şekil 6'daki adsorpsiyon verilerinden hesaplanmış izoterm sabitleri Tablo 4'de gösterilmiştir. As(V) adsorpsiyonu için, Langmuir izoterm modelinden sağlanmış korelasyon katsayıları $\left(\mathrm{R}^{2}\right) \mathrm{SP}$ ve Na-SP için sıra ile 0.95 ve 0.87 olmasına rağmen, Freundlich modeli için bu değerler sıra ile 0.93 ve 0.94 'dir. As(V) için her iki model uyum sağlamasına rağmen, $\mathrm{Na}$-SP ile $\mathrm{As}(\mathrm{V})$ 'in adsorpsiyonu için Freundlich modeli daha iyi uyumludur.

SP ve Na-SP ile As(III)'in adsorpsiyonu için, Langmuir izoterm model her iki adsorbent için yüksek uygunluğa sahiptir. SP ve Na-SP ile As(V)'in maksimum adsorpsiyon kapasitesi sira ile 10.52 ve $38.46 \mathrm{mg} \mathrm{g}^{-1}$ olup, $\mathrm{NaOH}$ ile muamele, doğal sepiyolitin kapasitesini yaklaşık 4 kata kadar artırmaktadır.

Tablo 4'de görüldüğü gibi, benzer bulgular, SP ve Na-SP ile As(III)'in adsorpsiyonu için de gözlenmiştir. Bu bulgular, adsorbentin karakterizasyon sonuçları temel alındığında, üç parametrenin bir sonucu olabilmektedir: (i)Yapıda sodyum magnezyum silikatların oluşumu, (ii) artan güçlü asit merkezlerin sayıs1 (iii) dekatyonizasyon ve desilikasyon ile yüzeyin modifikasyonu.

Langmuir parametrelerinden hesaplanmış Qm dengede tek tabakalı adsorpsiyonu göstermekte ve b parametresi ise As (III\&V) için bağlanma afinitesini göstermektedir. Yüksek b değeri temel alındığında, arsenik iyonları için Na-SP'in afinitesi SP'den yüksektir.

Freundlich izotermlerinden hesaplanmış $\mathrm{k}_{\mathrm{F}}$ sabitinin değeri adsorbentin tipine bağlı olarak değişmektedir. Örneklerin $1 / \mathrm{n}$ değeri 0 ve 1 aralığındadır ve güçlü adsorpsiyon kapasitesini göstermektedir [45]. SP ile As(III)'in adsorpsiyonu dişında $1 / \mathrm{n}$ değerleri 0 ve 1 aralığındadır.

Doğal ve modifiye edilmiş sepiyolit ile arsenik adsorpsyonu için Şekil 6'da gösterilen sonuçlar kaydırılmış birinci mertebe, kaydırılmış ikinci mertebe ve partikül içi difüzyon modellerine uygulanmış ve sonuçlar Tablo 5'de özetlenmiştir. Tablo 5'de gösterilen parametreler ve korelasyon katsayıları dikkate alındığında, kaydırılmış ikinci mertebe model diğer iki modelden yüksek korelasyon katsayısına sahip olup, deneysel sonuçları çok daha iyi temsil etmektedir. $\mathrm{Bu}$ bulgu arseniğin adsorbentin gözeneklerinde adsorplandığını ve adsorpsiyon hızının, adsorbentin aktif merkezlerinin karesi ile orantılı olduğunu göstermektedir[46]-[48].

SP ile As(III \&V)' in adsorpsiyonu üzerine sıcaklığın etkisi çalışılmış ve termodinamik parametreler denklem (2.7) ve (2.8) temel alınarak hesaplanmıştır. Elde edilen sonuçlar Tablo 6'da gösterilmiştir. Gibbs serbest entalpi değişimi arseniğin her iki değerliği için negatif olup, adsorbentler yüzeyinde arseniğin adsorpsiyonu termodinamik olarak mümkündür (Tablo 6). SP için $\Delta \mathrm{G}^{\mathrm{o}}$ değerleri artan sıcaklıkla yaklaşık sabittir. As(III) için $\Delta \mathrm{H}^{\mathrm{o}}$ pozitif değerleri adsorpsiyonun endotermik olduğunu diğer yandan $\mathrm{As}(\mathrm{V})$ 'in adsorpsiyonu için $\Delta \mathrm{H}^{\mathrm{o}}$ negatif değeri adsorpsiyonun ekzotermik doğasını göstermektedir. As (III\& V) için $\Delta \mathrm{S}^{\circ}{ }^{\prime}$ in pozitif değerleri As iyonlarının artan başlangıç derişimleri ile azalıyor ve bu sıv1-katı ara yüzeyinde artan düzenliliği desteklemektedir.

\section{Mangan adsorpsiyonu}

Mn(II)'nin adsorpsiyonu sadece SP yüzeyinde çalışılmış ve adsorpsiyon süresi ve sicaklık ile adsorpsiyon kapasitesinin değişimi Şekil 7'de gösterilmiştir. SP ile Mn(II)'nin dengeye ulaşma süresi $40 \mathrm{dk}$ olup, SP'in kapasitesi artan sıcaklıkla artmakta olup, bu adsorpsiyonun endotermik doğasını göstermektedir. Ayrıca, Tablo 5'de $\Delta \mathrm{H}^{\mathrm{o}}$ 'in pozitif değeri bunu desteklemektedir. $\Delta \mathrm{S}^{\mathrm{o}}$ 'in pozitif değeri $\mathrm{Mn}$ (II) iyonlarının artan başlangıç derişimi ile artmakta olup, bu kat1- S1v1 ara yüzeyindeki düzensizliği göstermektedir.

Arsenik sonuçlarına benzer olarak, doğal ve modifiye edilmiş sepiyolit ile mangan adsorpsyonu için Şekil 7'de gösterilen sonuçlar ile yapılan hesaplamalar, korelasyon katsayıları dikkate alındığında, kaydırılmış ikinci mertebe 

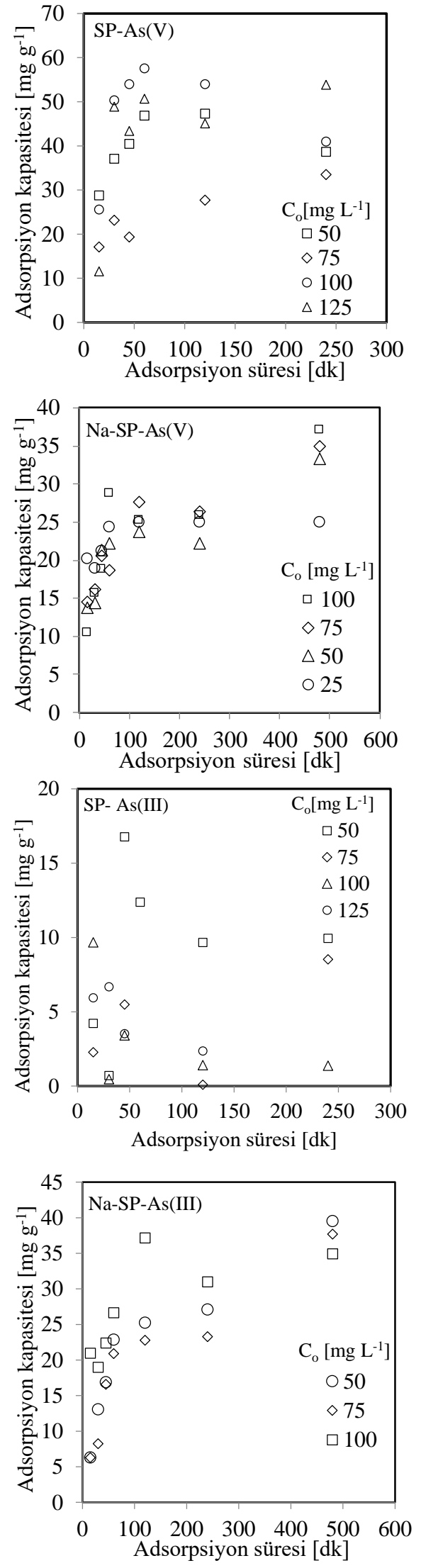

Şekil 6. As(III) ve As(V) için doğal ve modifiye edilmiş sepiyolitin kapasitesi ile adsorpsiyon süresinin değişimi $\left(\mathrm{T}=25^{\circ} \mathrm{C}, \mathrm{m}_{\text {adsorbent }}=0.02 \mathrm{~g}\right.$ ve $\mathrm{V}_{\text {çözelti }}=20 \mathrm{~cm}^{3}$, karıştırma hizi: $200 \mathrm{rpm})$. model ile verilerin çok daha iyi uyumlu olduğu görülmektedir.
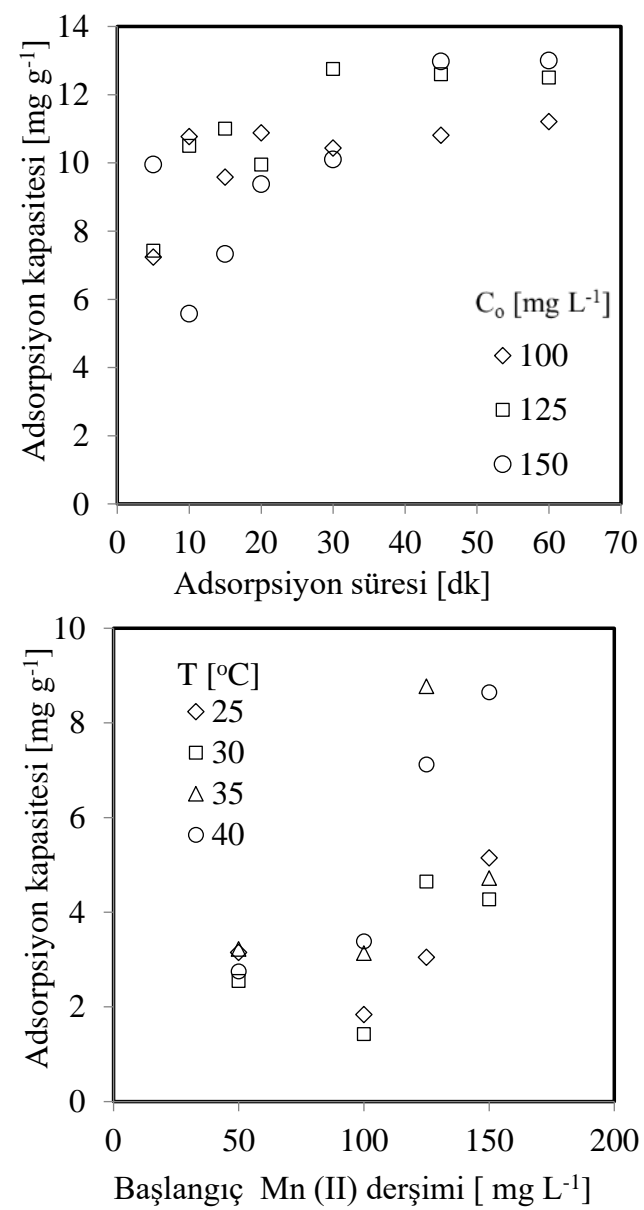

Şekil 7. Mn(II) adsorpsiyonu için doğal sepiyolitin adsorpsiyon süresinin ve sicaklığın bir fonksiyonu olarak adsorpsiyon kapasitesi $\left(\mathrm{m}_{\text {adsorbent }}=0.02 \mathrm{~g}\right.$ ve $\mathrm{V}_{\text {çözelti }}=20 \mathrm{~cm}^{3}$, karıştırma hızı: $200 \mathrm{rpm})$.

\section{Literatür ile sonuçların karşılaştırılması}

Sulu çözeltilerden arsenik türlerini uzaklaştırılmasında doğal sepiyolitin düşük adsorpsiyon kapasitesine sahip olduğu Tablo 4'de gösterilen ve literatürde rapor edilmiş sonuçlar [23], [24], [52], [54] ile gösterilmiştir. Doğal sepiyolitin $\mathrm{As}(\mathrm{V})$ adsorpsiyon kapasitesi, sepiyolitin kaynağına ve çözeltinin başlangıç pH'na bağlı olarak 0.005- $10.5 \mathrm{mg} \mathrm{g}^{-1}$ aralığında değişmektedir. Diğer yandan, $\mathrm{NaOH}, \mathrm{Fe}$ (III) oksihidroksit [24], [52], [53], [55] ve 2-aminometilpridin (AMP)[23] ile modifikasyonlar, sepiyolitin adsorpsiyon kapasitesini önemli miktarda artırabilmektedir. Literatürde rapor edilmiş sonuçlar, sepiyolitin çoğunlukla Fe (III) oksihidroksit ile modifiye edildiğinde ve başlangıç pH'ın değerine bağlı olarak sepiyolitin $\mathrm{As}(\mathrm{V})$ adsorpsiyon kapasitesinin $50.0 \mathrm{mg} \mathrm{g}^{-1}$ ' a kadar arttı̆̆ı rapor edilmiştir [24], [52], [55]. Bu çalışmada, $\mathrm{NaOH}$ ile modifiye edilmiş sepiyolit ilk olarak As(III\&V)'in ayrımında çalışılmış ve modifikasyon her iki arsenik değerliği için sepiyolitin adsorpsiyon kapasitesini 4 kata kadar artırmıştır. Benzer 
Tablo 4. As (III \&V) ve $\mathrm{Mn}$ (II)'in adsorpsiyon izoterm sabitleri $\left(\mathrm{Co}=100 \mathrm{mg} \mathrm{L}^{-1}, \mathrm{~T}=25^{\circ} \mathrm{C}\right.$, adsorpsiyon süresi: 8 saat, $\mathrm{m}_{\text {adsorbent }}=0.02 \mathrm{~g}$ ve Vçözelti $=20 \mathrm{~cm}^{3}$, karıştırma hızı: $\left.200 \mathrm{rpm}\right)$.

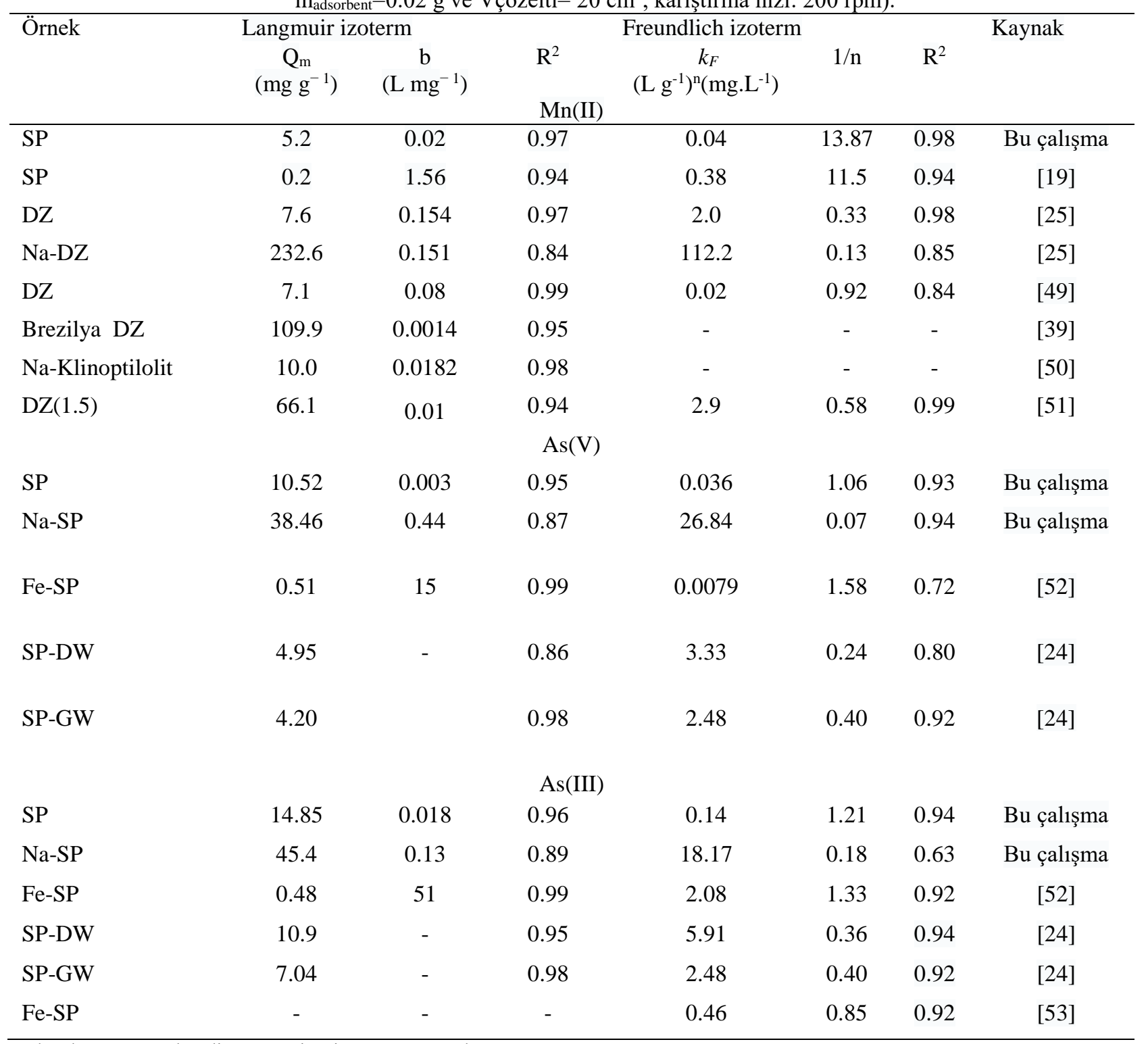

Kısaltmalar: DZ: Doğal zeolit; DW: Deiyonize su; GW: Yeraltı suyu

Tablo 5. Doğal ve modifiye edilmiş sepiyolit örneklerinin kinetik sonuçları $\left(\mathrm{Co}=50 \mathrm{mg} \mathrm{L}{ }^{-1}, \mathrm{~T}=25^{\circ} \mathrm{C}\right.$, adsorpsiyon süresi: 8 saat, $\mathrm{m}_{\text {adsorbent }}=0.1 \mathrm{~g}, \mathrm{Vçözelti}=100 \mathrm{~cm}^{3}$, karıştırma hızı: $1500 \mathrm{rpm}$ ).

\begin{tabular}{|c|c|c|c|c|c|c|c|c|c|c|}
\hline & & \multicolumn{3}{|c|}{ Kaydırılmış birinci mertebe } & \multicolumn{3}{|c|}{ Kaydırılmış ikinci mertebe } & \multicolumn{3}{|c|}{ Partikül ici difüzyon } \\
\hline $\mathrm{C}_{\mathrm{o}}\left(\mathrm{mg} \mathrm{L}^{-1}\right)$ & $\mathrm{qe}\left(\mathrm{mg} \mathrm{g}^{-1}\right)$ & $\mathrm{k}_{1}$ & $\mathrm{qe}\left(\mathrm{mg} \mathrm{g}^{-1}\right)$ & $\mathrm{R}^{2}$ & $\mathrm{k}_{2}$ & $\mathrm{qe}\left(\mathrm{mg} \mathrm{g}^{-1}\right)$ & $\mathrm{R}^{2}$ & $\mathrm{kd}$ & $\mathrm{C}$ & $\mathrm{R}^{2}$ \\
\hline \multicolumn{11}{|c|}{ SP-As(III) } \\
\hline 50 & 12.37 & 0.01 & 2.80 & 0.73 & $5.21 \times 10^{-5}$ & 60.71 & 0.95 & 0.56 & 18.0 & 0.78 \\
\hline \multicolumn{11}{|c|}{$\mathrm{Na}-\mathrm{SP}$ As(III) } \\
\hline 50 & 39.52 & 0.03 & 4.83 & 0.95 & 0.0018 & 36.49 & 0.96 & 5.88 & 5.8 & 0.98 \\
\hline \multicolumn{11}{|c|}{ SP-As(V) } \\
\hline 50 & 47.33 & 0.03 & 4.35 & 0.98 & 0.002 & 46.08 & 0.98 & 2.59 & 22.1 & 0.80 \\
\hline \multicolumn{11}{|c|}{$\mathrm{Na}-\mathrm{SP}-\mathrm{As}(\mathrm{V})$} \\
\hline 50 & 33.36 & 0.01 & 3.66 & 0.74 & 0.005 & 23.47 & 0.99 & 0.91 & 12.1 & 0.80 \\
\hline \multicolumn{11}{|c|}{ SP-Mn(II) } \\
\hline 50 & 11.2 & 0.002 & 1.80 & 0.98 & 0.05 & 9.22 & 0.99 & 0.58 & 7.4 & 0.44 \\
\hline
\end{tabular}


Tablo 6. Doğal ve NaOH ile muamele edilmiş sepiyolit ile Mn (II) ve As (III\& V) için termodinamik veriler.

\begin{tabular}{|c|c|c|c|c|c|c|}
\hline Örnek & & $\begin{array}{l}\mathrm{T} \\
(\mathrm{K})\end{array}$ & $\begin{array}{l}\Delta \mathrm{G}^{\mathrm{o}} \\
\left(\mathrm{kJmol}^{-1}\right)\end{array}$ & $\begin{array}{l}\Delta \mathrm{H}^{\mathrm{o}} \\
\left(\mathrm{kJmol}^{-1}\right)\end{array}$ & $\begin{array}{l}\Delta \mathrm{S}^{\mathrm{o}} \\
\left(\mathrm{J} \mathrm{mol}^{-1} \mathrm{~K}^{-1}\right)\end{array}$ & $\mathrm{R}^{2}$ \\
\hline \multirow[t]{17}{*}{ SP } & \multicolumn{6}{|l|}{ Mn (II) } \\
\hline & \multirow[t]{4}{*}{$50 \mathrm{mg} \mathrm{L}^{-1}$} & 298 & -14.8 & \multirow[t]{4}{*}{-6.67} & \multirow[t]{4}{*}{28.3} & \multirow[t]{4}{*}{0.41} \\
\hline & & 303 & - & & & \\
\hline & & 308 & -15.6 & & & \\
\hline & & 313 & -15.3 & & & \\
\hline & \multirow[t]{4}{*}{$100 \mathrm{mg} \mathrm{L}^{-1}$} & 298 & - & \multirow[t]{4}{*}{74.7} & \multirow[t]{4}{*}{286.5} & \multirow[t]{4}{*}{0.82} \\
\hline & & 303 & -11.8 & & & \\
\hline & & 308 & -14.2 & & & \\
\hline & & 313 & -14.6 & & & \\
\hline & \multirow[t]{4}{*}{$125 \mathrm{mg} \mathrm{L}^{-1}$} & 298 & -13.6 & \multirow[t]{4}{*}{51.9} & \multirow[t]{4}{*}{220.7} & \multirow[t]{4}{*}{0.97} \\
\hline & & 303 & -15.2 & & & \\
\hline & & 308 & - & & & \\
\hline & & 313 & -17.0 & & & \\
\hline & \multirow[t]{4}{*}{$150 \mathrm{mg} \mathrm{L}^{-1}$} & 298 & - & \multirow[t]{4}{*}{6.60} & \multirow[t]{4}{*}{262.8} & \multirow[t]{4}{*}{0.84} \\
\hline & & 303 & -13.8 & & & \\
\hline & & 308 & -14.4 & & & \\
\hline & & 313 & -16.5 & & & \\
\hline \multirow[t]{13}{*}{ SP } & \multicolumn{6}{|l|}{$\operatorname{As}(\mathrm{V})$} \\
\hline & \multirow[t]{4}{*}{$50 \mathrm{mg} \mathrm{L}^{-1}$} & 298 & -22.8 & \multirow[t]{4}{*}{-70.3} & \multirow[t]{4}{*}{497.4} & \multirow[t]{4}{*}{0.80} \\
\hline & & 303 & -18.0 & & & \\
\hline & & 308 & -17.9 & & & \\
\hline & & 313 & -19.1 & & & \\
\hline & $75 \mathrm{mg} \mathrm{L}^{-1}$ & 298 & -16.2 & -52.7 & 122.6 & 0.93 \\
\hline & & 303 & -15.2 & & & \\
\hline & & 308 & -15.2 & & & \\
\hline & & 313 & -14.2 & & & \\
\hline & $100 \mathrm{mg} \mathrm{L}^{-1}$ & 298 & -15.8 & -40.7 & 83.2 & 0.78 \\
\hline & & 303 & - & & & \\
\hline & & 308 & -15.7 & & & \\
\hline & & 313 & -14.2 & & & \\
\hline SP & As(III) & & & & & \\
\hline & $50 \mathrm{mg} \mathrm{L}^{-1}$ & 298 & -12.9 & 112.7 & 472.0 & 0.72 \\
\hline & & 303 & - & & & \\
\hline & & 308 & -20.8 & & & \\
\hline & & 313 & -19.5 & & & \\
\hline & $75 \mathrm{mg} \mathrm{L}^{-1}$ & 298 & - & 77.3 & 294.0 & 0.99 \\
\hline & & 303 & -11.7 & & & \\
\hline & & 308 & -12.2 & & & \\
\hline & & 313 & -14.6 & & & \\
\hline & $100 \mathrm{mg} \mathrm{L}^{-1}$ & 298 & - & 82.4 & 312.3 & 0.99 \\
\hline & & 303 & -12.2 & & & \\
\hline & & 308 & -13.8 & & & \\
\hline & & 313 & -15.4 & & & \\
\hline
\end{tabular}

olarak, Tian vd. [55], sepiyolitin manyetik demir oksit partikülleri ile modifiye ettiklerinde, maksimum As(III) adsorpsiyon kapasitesini $50.35 \mathrm{mg} \mathrm{g}^{-1}$ ' a kadar artırmışlardır. Gupta vd. [56] aglomere olmuş nano yapılı sentetik Fe(III)$\mathrm{Zr}(\mathrm{V})$ bimetalik adsorbent ile $9.3 \mathrm{mg} \mathrm{g}^{-1}$ maksimum As(V) adsopsiyon kapasitesini rapor etmişlerdir. Hlavay ve Polyak
[57], [58] demir alümina adsorbenti ile adsopsiyonun işletme koşullarına bağlı olarak(pH ve adsorbent miktarı) As(III) için $7.65 \mathrm{mg} \mathrm{g}^{-1}$ ve $\mathrm{As}(\mathrm{V})$ için $36.6 \mathrm{mg} \mathrm{g}^{-1}$ maksimum adsorpsiyon kapasitesini rapor etmişlerdir. Ren vd. [59] $\mathrm{Fe}-\mathrm{Zr}$ bimetalik adsorbenti ile maksimum As(III) adsorpsiyon kapasitesini $120 \mathrm{mg} \mathrm{g}^{-1}$ ve $\mathrm{As}(\mathrm{V})$ adsorpsiyon 
$46.0 \mathrm{mg} \mathrm{g}^{-1}(\mathrm{pH}=7)$ olarak rapor etmişlerdir. Zhang vd. [60] ise Fe- Mn bimetalik adsorbent ile As(III) ve As(V) için adsorpsiyon kapasitesini sırayla 69.7 ve $132.7 \mathrm{mg} \mathrm{g}^{-1}$ rapor etmiştir. $\mathrm{Na}$ içeren sepiyolit örnekleri ise, arsenik türlerini uzaklaştırmada demir ile modifiye edilmiş sepiyolitlere ve bimetalik adsorbentlerin adsorpsiyon kapasitesine yakın sonuçlar verebilmektedir.

Mn(II)'nin sulu çözeltilerden sepiyolit ile ayrımının literatür ile karşılaştırılması Tablo 4'de listelenmiştir. Tablodaki verilere göre SP'in adsorpsiyon kapasitesinin Kocaoba [19]'nın bulgularından yüksek ve doğal zeolitler ile [25], [39], [50], [51] karşılaştırılabilir olduğunu göstermektedir. Doğal sepiyolit örnekleri arasındaki farklılık sepiyolitin bileşim ve kaynağının bir sonucudur.

\section{DEĞERLENDİRME VE SONUÇ}

Sulu çözeltilerden arsenik türlerinin ve manganın adsorpsiyon prosesi ile uzaklaştırılması için doğal sepiyolit ve $\mathrm{NaOH}$ ile muamele edilmiş sepiyolit örnekleri karakterize edilmiştir. Doğal sepiyolit $187.8 \mathrm{~m}^{2} \mathrm{~g}^{-1}$ yüzey alanına sahip olup, sepiyolit mineral faz bileşime sahiptir. $\mathrm{NaOH}$ ile muamele sonrası, sepiyolitin ortalama gözenek çap1 silisyumun ve magnezyumun çözünmesi sonucu büyümekte, yapıda sodyum magnezyum silikat fazları oluşmakta ve silisyum türlerinde aglomerasyon oluşması nedeniyle, yüzey alanı $7 \mathrm{~m}^{2} \mathrm{~g}^{-1}$ 'e azalmıştır. Ayrıca, $\mathrm{NH}_{3-}$ TPD ile sepiyolitin yüzey asitliği incelenmesi, $\mathrm{NaOH}$ ile muamele ile zayıf ve orta güçlü Lewis/ Bronsted asit merkezlerinde azalma ve güçlü asit merkezlerinde ise artış belirlenmiş olup, bu yapıda oluşmuş sodyum magnezyum silikat türlerinin oluşumu ve $\mathrm{OH}^{-}$gruplarının uzaklaşması ile ilişkili olabilmektedir. $\mathrm{NaOH}$ ile sepiyolitin muamelesi her iki arsenik türünün adsorpsiyon kapasitesini önemli miktarda artırmıștır. Sepiyolitin alkali muamele ile artan adsorpsiyon kapasitesi, yapıda oluşmuş olan sodyum magnezyum silikatın sonucu, Na-sepiyolitin iyon değişim kapasitesinin artmasının bir sonucu olabilmektedir. Kaydırılmış ikinci mertebeden kinetik model doğal ve alkali ile muamele edilmiş sepiyolitler ile arsenik ve mangan giderimi için yüksek korelasyon katsayısına sahiptir.

\section{KAYNAKÇA}

[1] M. Bissen and F. H. Frimmel, "Arsenic - A review. Part I: Occurrence, toxicity, speciation, mobility," Acta Hydrochim. Hydrobiol., vol. 31, no. 1, pp. 9-18, 2003.

[2] N. E. Korte and Q. Fernando, "A review of arsenic (III) in groundwater," Crit. Rev. Environ. Control, vol. 21, no. 1, pp. 1-39, 1991.

[3] P. Mondal, C. B. Majumder, and B. Mohanty, "Laboratory based approaches for arsenic remediation from contaminated water: Recent developments," J. Hazard. Mater., vol. 137, no. 1, pp. 464-479, 2006.

[4] H. Bessbousse, T. Rhlalou, J. F. Verchère, and L. Lebrun, "Removal of heavy metal ions from aqueous solutions by filtration with a novel complexing membrane containing poly(ethyleneimine) in a poly(vinyl alcohol) matrix," J. Memb. Sci., vol. 307, no. 2, pp. 249-259, 2008. [5] M. J. González-Muñoz, M. A. Rodríguez, S. Luque, and J. R. Álvarez, "Recovery of heavy metals from metal industry waste waters by chemical precipitation and nanofiltration," Desalination, vol. 200, no. 1-3, pp. 742-744, 2006.

[6] C. G. Passos, F. S. Ribaski, N. M. Simon, A. A. dos Santos, J. C. P. Vaghetti, E. V. Benvenutti, and É. C. Lima, "Use of statistical design of experiments to evaluate the sorption capacity of 7-amine-4-azaheptylsilica and 10amine- 4-azadecylsilica for $\mathrm{Cu}(\mathrm{II}), \mathrm{Pb}(\mathrm{II})$, and $\mathrm{Fe}(\mathrm{III})$ adsorption," J. Colloid Interface Sci., vol. 302, no. 2, pp. 396-407, 2006.

[7] O. S. Amuda, A. A. Giwa, and I. A. Bello, "Removal of heavy metal from industrial wastewater using modified activated coconut shell carbon," Biochem. Eng. J., vol. 36, no. 2, pp. 174-181, 2007.

[8] R. Kiefer, A. I. Kalinitchev, and W. H. Höll, "Column performance of ion exchange resins with aminophosphonate functional groups for elimination of heavy metals," React. Funct. Polym., vol. 67, no. 12 SPEC. ISS., pp. 1421-1432, 2007.

[9] S. Babel, "Low-cost adsorbents for heavy metals uptake from contaminated water: a review," J. Hazard. Mater., vol. 97, no. 1-3, pp. 219-243, 2003.

[10] A. Alvarez, "Sepiolite: Properties and Uses," Dev. Sedimentol., vol. 37, no. C, pp. 253-287, 1984.

[11] K. Brauner and A. Preisinger, "Struktur und Entstehung des Sepioliths," Tschermaks Mineral. und Petrogr. Mitteilungen, vol. 6, no. 1-2, pp. 120-140, 1956.

[12] R. E. Grim, Clay Mineralogy, vol. 135. 1962.

[13] A. R. Türker, H. Bağ, and B. Erdoğan, "Determination of iron and lead by flame atomic absorption spectrometry after preconcentration with sepiolite," Fresenius. J. Anal. Chem., vol. 357, no. 3, pp. 351-353, 1997.

[14] E. Álvarez-Ayuso and A. García-Sánchez, "Sepiolite as a feasible soil additive for the immobilization of cadmium and zinc," Sci. Total Environ., vol. 305, no. 13, pp. 1-12, 2003.

[15] N. Bektas, B. A. Agim, and S. Kara, "Kinetic and equilibrium studies in removing lead ions from aqueous solutions by natural sepiolite," J. Hazard. Mater., vol. 112, no. 1-2, pp. 115-122, 2004.

[16] M. F. Brigatti, L. Medici, and L. Poppi, "Sepiolite and industrial waste-water purification: Removal of $\mathrm{Zn} 2+$ and $\mathrm{Pb} 2+$ from aqueous solutions," Appl. Clay Sci., vol. 11, no. 1, pp. 43-54, 1996.

[17] M. F. Brigatti, C. Lugli, and L. Poppi, "Kinetics of heavy-metal removal and recovery in sepiolite," in Applied Clay Science, 2000, vol. 16, no. 1-2, pp. 45-57.

[18] M. Kara, H. Yuzer, E. Sabah, and M. S. Celik, "Adsorption of cobalt from aqueous solutions onto sepiolite," Water Res., vol. 37, no. 1, pp. 224-232, 2003.

[19] S. Kocaoba, "Adsorption of $\mathrm{Cd}(\mathrm{II}), \mathrm{Cr}(\mathrm{III})$ and $\mathrm{Mn}(\mathrm{II})$ on natural sepiolite," Desalination, vol. 244, no. 1-3, pp. 24-30, 2009. 
[20] S. Lazarević, I. Janković-Častvan, D. Jovanović, S. Milonjić, D. Janaćković, and R. Petrović, "Adsorption of $\mathrm{Pb} 2+, \mathrm{Cd} 2+$ and $\mathrm{Sr} 2+$ ions onto natural and acid-activated sepiolites," Appl. Clay Sci., vol. 37, no. 1-2, pp. 47-57, 2007.

[21] V. Marjanović, S. Lazarević, I. Janković-Častvan, B. Potkonjak, D. Janaćković, and R. Petrović, "Chromium (VI) removal from aqueous solutions using mercaptosilane functionalized sepiolites," Chem. Eng. J., vol. 166, no. 1, pp. 198-206, 2011.

[22] L. I. Vico, "Acid-base behaviour and $\mathrm{Cu} 2+$ and $\mathrm{Zn} 2+$ complexation properties of the sepiolite/water interface," Chem. Geol., vol. 198, no. 3-4, pp. 213-222, 2003.

[23] D. L. Guerra, A. C. Batista, P. C. Corrêa da costa, R. R. Viana, and C. Airoldi, "Adsorption of arsenic ions on Brazilian sepiolite: Effect of contact time, $\mathrm{pH}$, concentration, and calorimetric investigation," J. Colloid Interface Sci., vol. 346, no. 1, pp. 178-187, 2010.

[24] N. Ilic, S. Lazarevic, V. Rajakovic-Ognjanovic, L. Rajakovic, D. Janackovic, and R. Petrovic, "The sorption of inorganic arsenic on modified sepiolite: Effect of hydrated iron(III)-oxide," J. Serbian Chem. Soc., vol. 79, no. 7, pp. 815-828, 2014.

[25] A. Ates, "Role of modification of natural zeolite in removal of manganese from aqueous solutions," Powder Technol., vol. 264, pp. 86-95, 2014.

[26] X. jiang Hu, J. song Wang, Y. guo Liu, X. Li, G. ming Zeng, Z. lei Bao, X. xia Zeng, A. wei Chen, and F. Long, "Adsorption of chromium (VI) by ethylenediaminemodified cross-linked magnetic chitosan resin: Isotherms, kinetics and thermodynamics," J. Hazard. Mater., vol. 185, no. 1, pp. 306-314, 2011.

[27] Y. S. Ho and G. McKay, "The kinetics of sorption of divalent metal ions onto sphagnum moss peat," Water Res., vol. 34, no. 3, pp. 735-742, 2000.

[28] M. Ghasemi, M. Zeinaly Khosroshahy, A. Bavand Abbasabadi, N. Ghasemi, H. Javadian, and M. Fattahi, "Microwave-assisted functionalization of Rosa Canina-L fruits activated carbon with tetraethylenepentamine and its adsorption behavior toward $\mathrm{Ni}(\mathrm{II})$ in aqueous solution: Kinetic, equilibrium and thermodynamic studies," Powder Technol., vol. 274, pp. 362-371, 2015.

[29] E. Malkoc and Y. Nuhoglu, "Potential of tea factory waste for chromium(VI) removal from aqueous solutions: Thermodynamic and kinetic studies," Sep. Purif. Technol., vol. 54, no. 3, pp. 291-298, 2007.

[30] S. Chen, Q. Yue, B. Gao, Q. Li, and X. Xu, "Removal of $\mathrm{Cr}(\mathrm{VI})$ from aqueous solution using modified corn stalks: Characteristic, equilibrium, kinetic and thermodynamic study," Chem. Eng. J., vol. 168, no. 2, pp. 909-917, 2011.

[31] G. W. Brindley, "Identification of Clay Minerals by X-ray Diffraction Analysis," Clays Clay Miner., vol. 1, no. 1, pp. 119-129, 1952.

[32] Y. Li, S. Liu, Z. Zhang, S. Xie, X. Zhu, and L. Xu, "Aromatization and isomerization of 1-hexene over alkalitreated HZSM-5 zeolites: Improved reaction stability,” Appl. Catal. A Gen., vol. 338, no. 1-2, pp. 100-113, 2008.
[33] I. Melián-Cabrera, S. Espinosa, C. Mentruit, F. Kapteijn, and J. A. Moulijn, "Alkaline leaching for synthesis of improved Fe-ZSM5 catalysts," Catal. Commun., vol. 7, no. 2, pp. 100-103, 2006.

[34] I. Melián-Cabrera, S. Espinosa, J. C. Groen, B. V. D. Linden, F. Kapteijn, and J. A. Moulijn, "Utilizing fullexchange capacity of zeolites by alkaline leaching: Preparation of Fe-ZSM5 and application in N2O decomposition," J. Catal., vol. 238, no. 2, pp. 250-259, 2006. [35] J. Jänchen, R. V. Morris, D. L. Bish, M. Janssen, and U. Hellwig, "The $\mathrm{H} 2 \mathrm{O}$ and $\mathrm{CO} 2$ adsorption properties of phyllosilicate-poor palagonitic dust and smectites under martian environmental conditions," Icarus, vol. 200, no. 2, pp. 463-467, 2009.

[36] F. R. Cannings, "An infrared study of hydroxyl groups on sepiolite," Journal of Physical Chemistry, vol. 72, no. 3. pp. 1072-1074, 1968.

[37] C. Serna, J. L. Ahlrichs, and J. M. Serratosa, "Folding in sepiolite crystals," Clays Clay Miner., vol. 23, no. 6, pp. 452-457, 1975.

[38] Y. T. Kim, K. D. Jung, and E. D. Park, "Gas-phase dehydration of glycerol over silica-alumina catalysts," Appl. Catal. B Environ., vol. 107, no. 1-2, pp. 177-187, 2011.

[39] G. L. Woolery, G. H. Kuehl, H. C. Timken, A. W. Chester, and J. C. Vartuli, "On the nature of framework Brønsted and Lewis acid sites in ZSM-5," Zeolites, vol. 19, no. 4, pp. 288-296, 1997.

[40] G. Zhang, J. Qu, H. Liu, R. Liu, and R. Wu, "Preparation and evaluation of a novel Fe-Mn binary oxide adsorbent for effective arsenite removal," Water Res., vol. 41, no. 9, pp. 1921-1928, 2007.

[41] A. Günay, E. Arslankaya, and I. Tosun, "Lead removal from aqueous solution by natural and pretreated clinoptilolite: Adsorption equilibrium and kinetics," J. Hazard. Mater., vol. 146, no. 1-2, pp. 362-371, 2007.

[42] A. Cincotti, N. Lai, R. Orrù, and G. Cao, "Sardinian natural clinoptilolites for heavy metals and ammonium removal: Experimental and modeling," Chem. Eng. J., vol. 84, no. 3, pp. 275-282, 2001.

[43] A. H. Englert and J. Rubio, "Characterization and environmental application of a Chilean natural zeolite," Int. J. Miner. Process., vol. 75, no. 1-2, pp. 21-29, 2005.

[44] L. L??, L. Chen, W. Shao, and F. Luo, "Equilibrium and kinetic modeling of $\mathrm{Pb}$ (II) biosorption by a chemically modified orange peel containing Cyanex 272," J. Chem. Eng. Data, vol. 55, no. 10, pp. 4147-4153, 2010.

[45] Y. Tao, H. Kanoh, and K. Kaneko, "Developments and structures of mesopores in alkaline-treated ZSM-5 zeolites," Adsorption, vol. 12, no. 5-6, pp. 309-316, 2006.

[46] T. A. Khan, S. A. Chaudhry, and I. Ali, "Equilibrium uptake, isotherm and kinetic studies of Cd(II) adsorption onto iron oxide activated red mud from aqueous solution,” J. Mol. Liq., vol. 202, pp. 165-175, 2015.

[47] V. O. Leone, M. C. Pereira, S. F. Aquino, L. C. A. Oliveira, S. Correa, T. C. Ramalho, L. V. A. Gurgel, and A. C. Silva, "Adsorption of diclofenac on a magnetic adsorbent based on maghemite: experimental and theoretical studies," New J. Chem., vol. 42, no. 1, pp. 437-449, 2018. 
[48] Y. S. Ho and G. McKay, "Pseudo-second order model for sorption processes," Process Biochem., vol. 34, no. 5, pp. 451-465, 1999.

[49] Y. Tae, K. Jung, and E. Duck, "Microporous and Mesoporous Materials Gas-phase dehydration of glycerol over ZSM-5 catalysts," Microporous Mesoporous Mater., vol. 131, no. 1-3, pp. 28-36, 2010.

[50] D. Esquivel, A. J. Cruz-Cabeza, C. JiménezSanchidrián, and F. J. Romero-Salguero, "Local environment and acidity in alkaline and alkaline-earth exchanged ?? zeolite: Structural analysis and catalytic properties," Microporous Mesoporous Mater., vol. 142, no. 2-3, pp. 672-679, 2011.

[51] A. Ates and G. Akg??1, "Modification of natural zeolite with $\mathrm{NaOH}$ for removal of manganese in drinking water," Powder Technol., vol. 287, pp. 285-291, 2016.

[52] N. Bektas, S. Aydin, and M. S. Oncel, "The Adsorption of Arsenic Ions Using Beidellite, Zeolite, and Sepiolite Clays: A Study of Kinetic, Equilibrium and Thermodynamics," Sep. Sci. Technol., vol. 46, no. 6, pp. 1005-1016, 2011.

[53] M. D. Öztel, F. Akbal, and L. Altaş, “Arsenite removal by adsorption onto iron oxide-coated pumice and sepiolite," Environ. Earth Sci., vol. 73, no. 8, pp. 4461-4471, 2015.

[54] S. A. Alex, C. Lomenech, C. Hurel, and N. Marmier, "Adsorption of nickel and arsenic from aqueous solution on natural sepiolite,” Int. J. Nanotechnol., vol. 9, no. 3/4/5/6/7, p. 204, 2012.

[55] N. Tian, X. Tian, L. Ma, C. Yang, Y. Wang, Z. Wang, and L. Zhang, "Well-dispersed magnetic iron oxide nanocrystals on sepiolite nanofibers for arsenic removal," RSC Adv., vol. 5, no. 32, pp. 25236-25243, 2015.

[56] K. Gupta, T. Basu, and U. C. Ghosh, "Sorption characteristics of $\operatorname{arsenic}(\mathrm{V})$ for removal from water using agglomerated nanostructure iron(III)-zirconium(IV) bimetal mixed oxide," J. Chem. Eng. Data, vol. 54, no. 8, pp. 2222 2228, 2009.

[57] J. Hlavay and K. Polyák, "Determination of surface properties of iron hydroxide-coated alumina adsorbent prepared for removal of arsenic from drinking water," J. Colloid Interface Sci., vol. 284, no. 1, pp. 71-77, 2005.

[58] J. Hlavay and K. Polyak, "Determination of surface properties of iron hydroxide-coated alumina adsorbent prepared for removal of arsenic from drinking water.," J. Colloid Interface Sci., vol. 284, no. 1, pp. 71-77, 2005.

[59] Z. Ren, G. Zhang, and J. Paul Chen, "Adsorptive removal of arsenic from water by an iron-zirconium binary oxide adsorbent," J. Colloid Interface Sci., vol. 358, no. 1, pp. 230-237, 2011.

[60] G. Zhang, J. Qu, H. Liu, R. Liu, and R. Wu, "Preparation and evaluation of a novel Fe-Mn binary oxide adsorbent for effective arsenite removal," Water Res., vol. 41, no. 9, pp. 1921-1928, 2007. 